\title{
THE CHRONIC ANAL FISSURE TREATMENT BY INTERNAL PARTIAL LATERAL SPHINCTEROTOMY AND FOLLOWING ANAL MANOMETRY
}

\author{
Dušan Šimkovič, Milan Široký, Karel Šmejkal \\ Department of Surgery, University Teaching Hospital, Hradec Králové; \\ (Head: doc. MUDr. J. Bedrna, CSc.) \\ Clinical Centre, Department of Biochemistry and Diagnostics, University Teaching Hospital, Hradec Králové; \\ (Head: doc. MUDr. J. Bureš, CSc.)
}

\begin{abstract}
Summary: Anal fissure remains one of the most common proctologic problems. A number of reports have advocated the use of partial internal sphincterotomy as a treatment of chronic anal fissure. Our study shows the results of a retrospective analysis of our patients who underwent lateral internal sphincterotomy for the treatment of chronic anal fissure.

To determine long time results we examined random sample of 75 operated patients. Apart from taking careful history and patient's assessment of the operation effect, the patients were investigated „per rectum“, and even possibly rectoscopically. To asscertain suitability and also security of properly done internal sphincterotomy, we performed anorectal manometric examinations in 53 patients controlled. To conclude our results, we can state that in $9(12 \%)$ patients controlled some subjective complaints or certain pathologic findings connected with anal fissure or sphincterotomy were found.

None of the people from the set of ours suffered from any complaints, which can be taken as stool incontinency. In no patients any change in pressure measured by anorectal manometry indicating incontinency was proved.
\end{abstract}

Key words: Chronic anal fissure; Internal lateral sphincterotomy

\section{Introduction}

Anal fissure remains one of the most common proctologic problems. Fissures are being seen in all age groups, although the majority of patients is represented by relatively young to middle-aged adults. Fissures cause considerable pain, irrelevant to the size of the lesion, resulting in significant morbidity and disability. Therefore, it is worthwhile to find and identify the most effective but safe treatments for this disease.

A number of reports $(6,8,9,10,12)$ have advocated the use of partial internal sphincterotomy as a treatment of chronic anal fissure. Surgical sphincterotomy promises the immediate relief of pain, it is simple to be performed and most patients express their satisfaction with the result. However, the complications of sphincterotomy generally may be represented by a disquieting incidence of postoperative incontinence to feces or flatus.

This study shows the result of a retrospective analysis of our patients who underwent lateral internal sphincterotomy for the treatment of chronic anal fissure.

\section{Patients and methods}

From January 1985 to December 1996, 133 patients ( 81 males, 52 females; average age 45,24 years) with chronic symptomatic anal fissures underwent surgical treatment using internal lateral sphincterotomy.

As chronic fissures we considered those (according to Tzu-Chi Hsu), in which at least two of following three symptoms - sentinel pile, fissure with sclerotic edges with revealed interior sphincter on the bottom and hypertrophic anal papilla - were present.

Most of the operations were performed by the author. Under general anesthesia in gynecological position the investigation of anal canal was done first. After careful differentiation of the internal sphincter the right sided internal sphincterotomy in necessary extent was performed while the anal canal tonus was controlled with left forefinger. We were not bound to performe internal sphincterotomy in any patient as far as to the area of linea dentata.After hemostasis by help of compression we performed the suture of the incision by one stitch. Sentinel pile and hypertrophic anal papilla were cut only in cases of their larger size.

Post operation treatment was simple, occasionally analgetics were given but dietetical restrictions were not necessary. In the anal hygiene we recommended short time sitting baths. After short hospitalization all patients were followed up in the outpatients department till total recovery.

To determine long time results we examined random sample of 75 (56\%) operated patients. From these indivi- 
duals there were 43 males, 32 females, average age, 45,12 years. Apart from taking careful history and patient's assessment of the operation effect, the patients were investigated „per rectum“, and even possibly rectoscopically.

To asscertain suitability and also security of properly done internal sphincterotomy we performed anorectal manometric examinations in 53 patients controlled.

\section{Results}

Having evaluated results of check ups we found that 70 controlled patients (93\%) take the operation results for very satisfactory or good. When we investigated these individuals digitally „per rectum“ we found no pathological change, which could have been in possible connection with anal fissure or sphincterotomy. Two patients from the set of ours complained of mild soiling, 2 other people occasionally had flatus control problems. In the two last mentioned ones we found manometric resting preassures at the lower limits within the normal range $(40 \mathrm{~mm} \mathrm{Hg})$.

One patient of ours took the operation results for being satisfactory. When investigated the patient had a submucous perianal fistule connected with sphincterotomy performance.

Only 4 patients considered the operation results as unsatisfactory ones. One of them had perianal fistule in the spot of sphincterotomy, 3 others had signs of fissure recurrency. Manometric measurement in two of those with fissure recurrences proved high levels of resting and squeeze pressures.

To conclude, we can state that in $9(12 \%)$ patients controlled some subjective complaints or certain pathologic findings connected with anal fissure or sphincterotomy were found.

None of the people from the set of ours suffered from any such complaints, which can be taken as stool incontinency. In no patient any change in pressure measured by anorectal manometry indicating incontinency was proved.

\section{Discussion}

Anal fissure remains one of the most commonly encountered proctologic problems. It affects both men and women of all ages. Its appearance is that of a relatively minor lesion, but anal fissure causes considerable pain and discomfort, by far disproportionate to its size. Fissures are most commonly found in the posterior midline. Identification of etiologic, as well as predisposing factors, may help to reduce the incidence of anal fissures.

Much work has been done to elucidate its etiology;however, a simple unification has not been established $(1,10)$.

Anal sphincteric measurements show that the maximal basal pressure is significantly higher in patients with anal fissures and when these patients are treated by sphincterotomy, the basal pressure is significantly reduced. These stu- dies suggest that increased pressure in the anal canal contributes to the pathophysiology of anal fissure $(2,4)$.

Till the middle of this century, posterior sphincterotomy was an accepted surgical treatment for chronic anal fissure (3). In 1969, Notaras (9) described a simpler and more effective method of partial lateral internal sphincterotomy. The advantage of this method over the posterior technique or stretching method was confirmed by Hawley (5) and Hoffman and Goligher (6).

Why some patients after partial sphincterotomy have transient or permanent postoperative incontinence of flatus or feces and others have not, is not clear, but the reason may be elucidated by the wide range of postoperative sphincter pressures. The lowest postoperative sphincter pressures reported are within the range usually associated with incontinence. These low pressures may result from sphincterotomy being carried out in patients with a fissure but with normal preoperative pressures (7).

Postoperative incontinence of flatus or feces, even if only mild soiling, may be extremely inconvenient. The conclusion reached by Pernikoff et al (11) in 1994 study of 500 sphincterotomies is representative to most of series. In spite of a long-term complication rate of $11 \%$ these authors state: „Partial lateral sphincterotomy is a highly succesful, safe procedure when performed carefully, selectively and under controlled circumstances“.

Surgical sphincterotomy is an excellent procedure for the long-term cure of chronic anal fissure. It probably works by reducing resting anal pressure by as much as $50 \%$. There is an evidence from laser Doppler studies that this may lead to improved perfusion of the pecten which might then facilitate healing of what are now known as relatively ischemic ulcers $(2,7)$.

\section{Conclusion}

Careful patient selection, absence of peroperative continence problems, and meticulous surgical techniques are necessary to achieve the type of results presented.

\section{References}

1. Arnous J, Denis J. Pathogenesis and concepts of anal fissure. Am J Proctol 1971;22:184-6.

2. Boulos PB, Araujo JGC. Adequate internal sphincterotomy for chronic anal fissure: subcutaneous or open technique? Br J Surg 1984;71:360.

3. Eisenhammer S. The surgical correction of chronic anal (sphinteric) contracture. S Afr Med J 1951;25:486-9.

4. Hancock BD. The internal sphincter and anal fissure. $\mathrm{Br}$ J Surg 1977;64:92.

5 Hawley PR. The treatment of chronic fissure-in-ano: a trial of methods. Br J Surg 1969;56:915-8.

6. Hoffman DC, Goligher JC. Lateral subcutaneous internal sphincterotomy in treatment of anal fissure. Br Med J 1970;3:673-5. 
7. Chowcat NL, Araujo JG, Boulos PB. Internal sphincterotomy for chronic anal fissure: long-term effects on anal pressure. Br J Surg 1986;73:915-6.

8. Millar DM. Subcutaneous lateral internal anal sphincterotomy for anal fissure Br J Surg 1971;58:737-9.

9. Notaras MJ. Lateral subcutaneous sphincterotomy for anal fissure: A new technique. Proc R Soc Med 1969;62:713.

10. Oh C. Lateral subcutaneous internal sphincterotomy for anal fissure. Mt Sinai J Med (NY) 1975;42:596-601.

11. Pernikoff BJ,Eisenstat TE, Rubin RJ, Oliver GC, Salvati

EP. Reappraisal of partial lateral internal sphincterotomy.

Dis Colon Rectum 1994;37:1291-5.
12. Rudd WW. Lateral subcutaneous internal sphincterotomy for anal fissure. Dis Colon Rectum 1975;18:319-23.

Submitted May 1997.

Accepted May 1997.

MUDr. Dušan Šimkovič, CSc.,

Cechova 759,

50002 Hradec Králové,

Czech Republic. 